Article

\title{
Novel Measurements of Fine-Scale Albedo: Using a Commercial Quadcopter to Measure Radiation Fluxes
}

\author{
Charlotte R. Levy ${ }^{1, *}$, Elizabeth Burakowski ${ }^{2}$ (ID) and Andrew D. Richardson ${ }^{3,4}$ \\ 1 Department of Ecology and Evolutionary Biology, Cornell University, Ithaca, NY 14850, USA \\ 2 Institute for the Study of Earth, Oceans, and Space, University of New Hampshire, \\ Durham, NH 03824, USA; elizabeth.burakowski@unh.edu \\ 3 School of Informatics, Computing and Cyber Systems, Northern Arizona University, \\ Flagstaff, AZ 86011, USA; andrew.richardson@nau.edu \\ 4 Center for Ecosystem Science and Society, Northern Arizona University, Flagstaff, AZ 86011, USA \\ * Correspondence: crl222@cornell.edu; Tel.: +1-857-636-9396
}

Received: 19 June 2018; Accepted: 15 August 2018; Published: 18 August 2018

\begin{abstract}
Remote sensing of radiative indices must balance spatially and temporally coarse satellite measurements with finer-scale, but geographically limited, in-situ surface measurements. Instruments mounted upon an Unmanned Aerial Vehicle (UAV) can provide small-scale, mobile remote measurements that fill this resolution gap. Here we present and validate a novel method of obtaining albedo values using an unmodified quadcopter at a deciduous northern hardwood forest. We validate this method by comparing simultaneous albedo estimates by UAV and a fixed tower at the same site. We found that UAV provided stable albedo measurements across multiple flights, with results that were well within the range of tower-estimated albedo at similar forested sites. Our results indicate that in-situ albedo measurements (tower and UAV) capture more site-to-site variation in albedo than satellite measurements. Overall, we show that UAVs produce reliable, consistent albedo measurements that can capture crucial surface heterogeneity, clearly distinguishing between different land uses. Future application of this approach can provide detailed measurements of albedo and potentially other vegetation indices to enhance global research and modeling efforts.
\end{abstract}

Keywords: albedo; land use; remote sensing; Unmanned Aerial Vehicles; vegetation indices

\section{Introduction}

Over the past few decades, the simultaneous rise of remote sensing technologies and earth system models has generated a broad, cross-disciplinary need for radiometric datasets with both global extent and fine-scale parameterization. Radiometric indices are used to estimate global primary productivity, vegetative cover, energy fluxes, and many more properties essential to understanding present and future climate and ecosystem functioning [1,2]. An uneven or too sparse global distribution of sites will bias estimates and cause these ecosystem properties to be poorly represented by global climate models [3,4]. At the same time, local disturbances (forest fires, drought, plowing, thinning, snow aging) [5-7] can have outsize effects on regional and global climate [5,8-11], yet be poorly captured by coarse global measurements or too underrepresented to be well modeled by earth system models $[12,13]$. To understand current and future trends in ecosystem functioning and climatic change, we must be able to capture both global extent and fine-scale variation in remotely-sensed, radiometric datasets $[6,14-20]$.

Patterns at the global scale are generally derived from broadband satellite products $[3,16,21,22]$, that are far-reaching but coarse-scaled. The most commonly used albedo dataset, the MODIS data products, are scaled as $500 \mathrm{~m}$ sinusoidal grid resolutions, limiting their ability to register small-scale 
land use and management strategies $[4,23,24]$. Development of a well-validated LANDSAT albedo product is ongoing and will provide a $30 \mathrm{~m}$ product at 16-day intervals, significantly improving the spatial resolution of the remotely-sensed albedo measurements; however, fine-scale in-situ estimates will still be needed to continue to validate this product $[7,25,26]$. In-situ measurements can corroborate satellite data but have their own limitations. Fixed towers are immobile, few in number, and have physical limitations on maximum height that limit their spatial range. Thus, scattered point measurements from towers may not accurately represent variation across larger landscapes [3,24]. Portable spectroradiometers have been used to quantify radiation fluxes in fields and the understory, and are generally very effective for evaluating effects of snow depth [27], snow age, grain size, and layer structure [28,29]. However these tools are limited in their application above canopy [27]. Airborne high-resolution hyperspectral sensors mounted on planes or helicopters have permitted quantification of radiation fluxes across broader regions, but tend to be extremely costly and logistically complex. They can capture only single time point measurements along the flight path and are subject to technical issues caused by the scattering of light by aerosols and water vapor at higher altitudes between the sensor and the land surface [27].

Unmanned aerial vehicles (UAVs) can increase both the flexibility and affordability of fine-scale measurements, providing an essential bridge between ground-truthing and global satellite data [30,31]. UAVs can move freely over tree canopies, allowing measurement over entire forest stands rather than just single points. UAVs can adjust to a range of canopy heights, giving them more flexibility to achieve optimal observation heights [24]. UAV flights are more affordable than piloted airborne missions; moreover, in the United States recent adjustments to Federal Aviation Administration regulations have made UAV technology more accessible for researchers [32]. Several caveats must be considered: flights are limited in range and flight time by the strength of the radio signal, the battery life, the payload, and the angle of view of the observer. Standards for accommodating any position or height instability must still be developed. Finally, adaptation of UAVs for measurement of radiative indices requiring both incoming and reflected radiation measurements has been technically difficult to make by UAVs due to issues of payload weight and balance. Albedo is the ratio between down-welling shortwave broadband solar radiation and reflected, up-welling shortwave broadband solar radiation; it is typically measured using paired (one upward facing, one downward facing) pyranometers. However, standard UAVs are generally designed to lift objects with a center of gravity beneath the vehicle, such that mounting an upward-facing pyranometer on top or on an extended boom off of an UAV requires extensive customization and technical adjustment to ensure flight stability. In addition, the weight of two sensors imposes a significant energy cost, greatly reducing flight time. Two previous studies measuring albedo via UAV (fixed-wing craft over the Indian Ocean [33], fixed-wing craft over Greenland [34]) have required custom modifications not swiftly replicable by most research labs. The simple method of measuring albedo proposed here allows use of unmodified quadcopters such as have been widely adopted by many labs for other forms of aerial imaging while minimizing payload and maximizing flight time.

Here we employ a novel measurement method to investigate albedo over a mixed hardwood forest in central New York. UAV measurements were tested for consistency across flights and for comparability to conventional forest albedo measurements made by tower and satellite. We verify the validity of our technique through side-by-side tower and UAV comparison over a field of shrub willow. Finally, we examine albedo across three land uses and seven flights, comparing within flight variability to variability across land uses. In testing this novel method, which minimizes UAV payload and permits use of uncustomized quadcopters, we hope to expand the capacity for scientists to validate satellite estimates using fine-scale radiometric measurements. 


\section{Materials and Methods}

\subsection{A Novel Method of Measuring Albedo by UAV}

In the method presented here, albedo was calculated as the ratio between reflected shortwave radiation, as measured from a downward-facing pyranometer mounted under a UAV, and incoming shortwave radiation, as measured from a separate upward-facing pyranometer mounted to a pole in an immediately adjacent open area (Figure 1). The UAV-mounted downward-facing pyranometer was a Kipp and Zonen CMP3 pyranometer (spectral range: 300-2800 nm). It was secured underneath a four-rotor Spyder 850 (Sky Hero, Pearland, TX, USA) UAV and leveled using a motorized Gaui Crane gimbal (Figure 2).

The UAV was only modified to the extent of having the carbon-fiber support legs lengthened, to provide additional clearance for the pyranometer during take-off and landing. The UAV pyranometer was paired with an upward-facing Kipp and Zonen CMP6 pyranometer (spectral range: 285-2800 nm) mounted on a pneumatic telescoping pole (Total Mast Solutions, CP56-08) and secured to a portable tripod. The pyranometer was fixed on a $30 \mathrm{~cm}$ leveled boom, oriented to the south, at a height of $9.09 \mathrm{~m}$ [35]. To obtain reference albedo measurements for validation flights, a second Kipp and Zonen CMP6 pyranometer was fixed and leveled below the first, to determine reflected radiation from beneath the tower. All instruments had a sensitivity of 5 to $20 \mu \mathrm{V} / \mathrm{W} / \mathrm{m}^{2}$, a response time of $18 \mathrm{sec}$ or less $(95 \%)$, and an effective half field of view of $81^{\circ}$. The thirty-second averages of up-welling and down-welling shortwave radiation from both pyranometers were recorded by an attached Kipp and Zonen METEON datalogger. The internal clocks of the two dataloggers were synchronized by a common laptop computer an hour prior to the experiment start. For each individual flight, the sum of all reflected radiation values was divided by the sum of incoming radiation values to get a flux-weighted albedo value for that flight. The viewing area of the pyranometer was calculated as the area from which $99 \%$ of sensor input came. This area was calculated based on Kipp and Zonen (2016) recommendations:

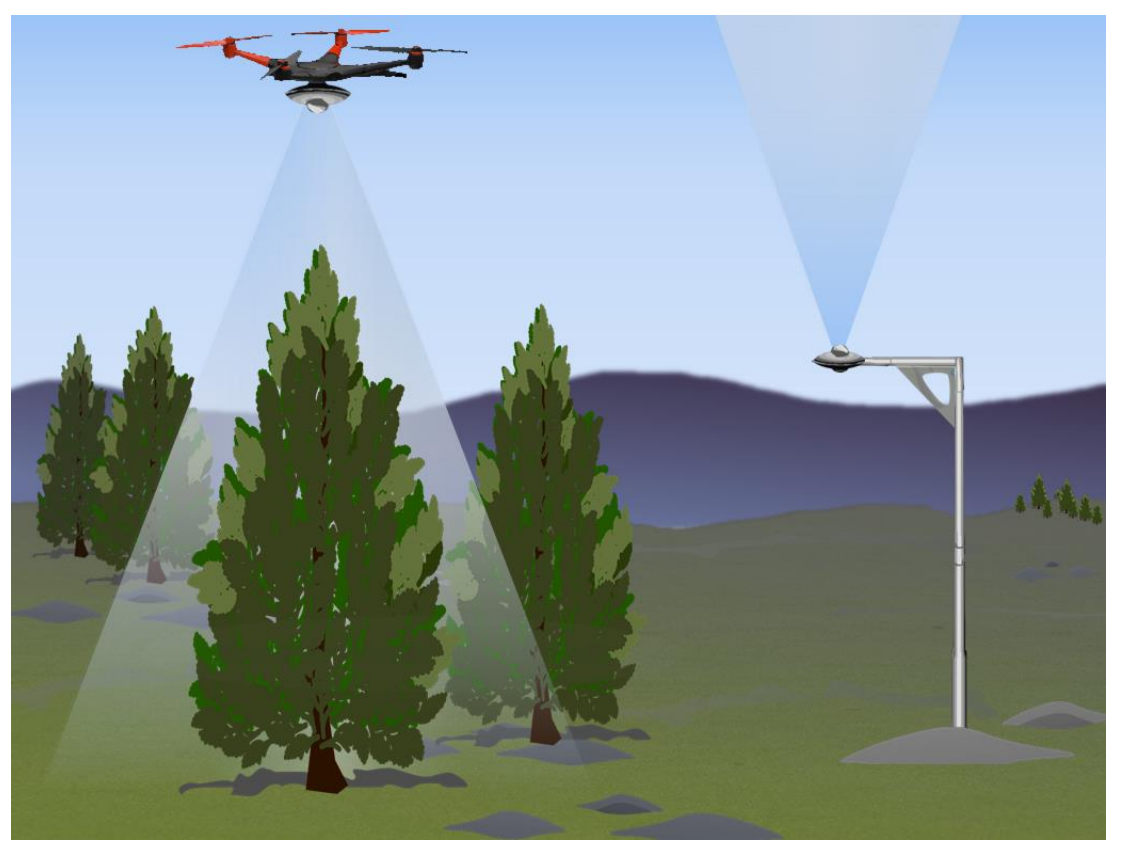

Figure 1. Diagram of flight design depicting the UAV with downward-facing pyranometer (left) and the fixed pole with the upward-facing pyranometer (right). 


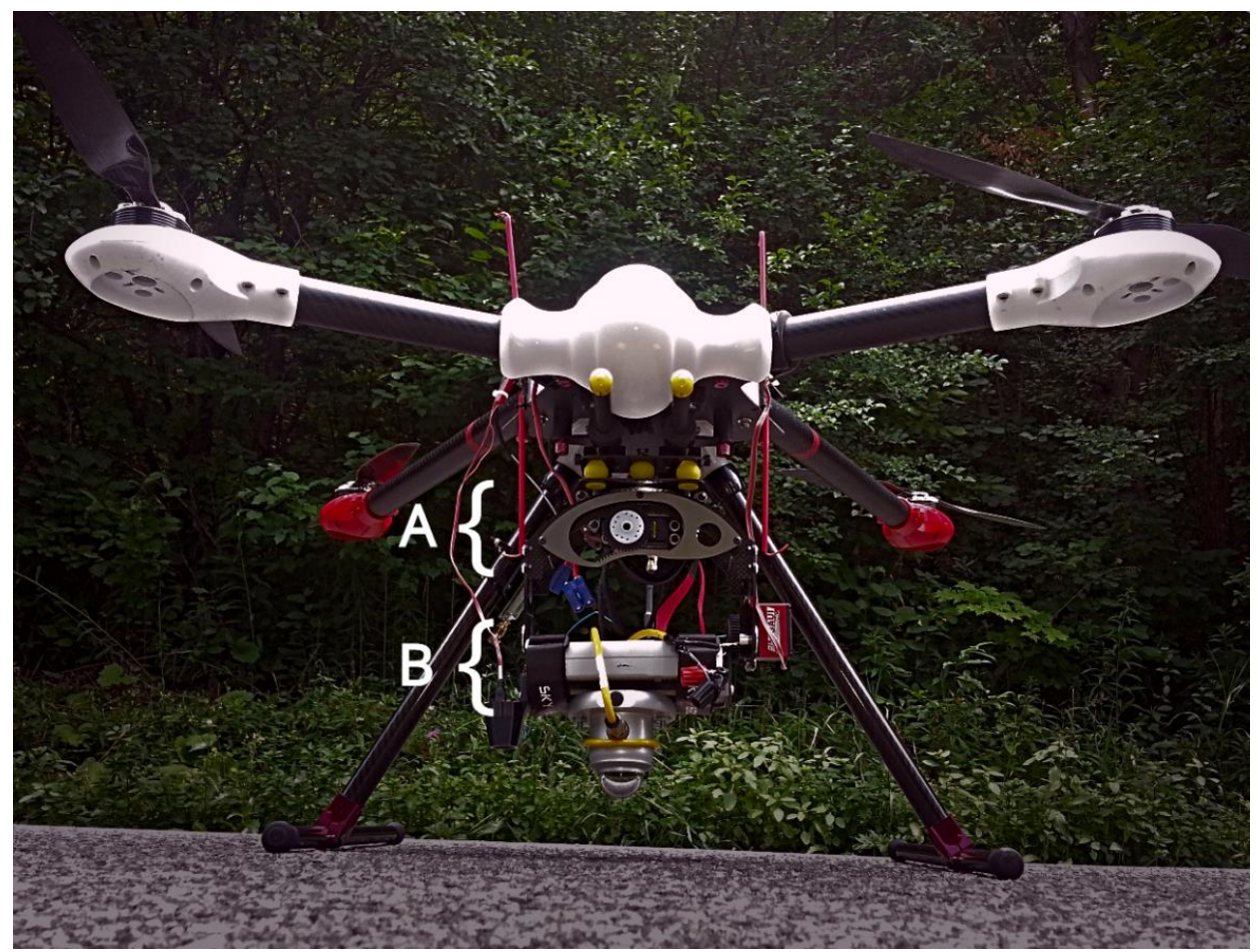

Figure 2. Preparation of the UAV for flight. The gimbal (A) is visible underneath the UAV, equipped with the downward-facing pyranometer secured beneath $(\mathbf{B})$.

\subsection{Experimental Design and Study Area}

Albedo measurements consisted of targeted forest measurements by UAV (Section 2.2.1), along with comparative measurements of similar forests by tower and satellite (Section 2.2.2), validating measurements over a local willow field by UAV and tower (Section 2.2.3), and a final comparison of UAV measurements of forest, field, and coniferous forest (Section 2.2.4). The targeted forest measurements demonstrated the internal consistency of UAV measurements, while tower and satellite measurements showed the comparability of UAV albedo to ground and satellite measurements at similar sites. Validation flights compared simultaneous UAV and tower albedo. Finally, the comparison of deciduous, coniferous, and willow sites contrasted the variability across flights with variability across land uses.

Targeted UAV surveys over mixed hardwood forest took place in Tully, NY, USA at a closed-canopy mixed northern hardwood forest stand (Figure 3b; Table 1). Comparative tower and satellite-based measurements from other mixed hardwood sites were obtained from three sites with existing long-term tower albedo measurements, in Bartlett, NH; Durham, NH; and Petersham, MA (Figure 3a; Table 1). All three sites represented a temperate climate and mixed northern hardwood forest land cover. Albedo at each comparative site was obtained from a fixed-point tower and from MODIS satellite data. Validation UAV flights took place in Geneva, NY, USA over a cropped willow field (July 2017), where low height of vegetation allowed both tools to be used simultaneously (Figure 3c; Table 1). Finally, additional UAV flights at a Norway spruce monoculture stand (July 2017) were combined with 2017 forest and willow data for a comparison of different land uses (Table 1). 


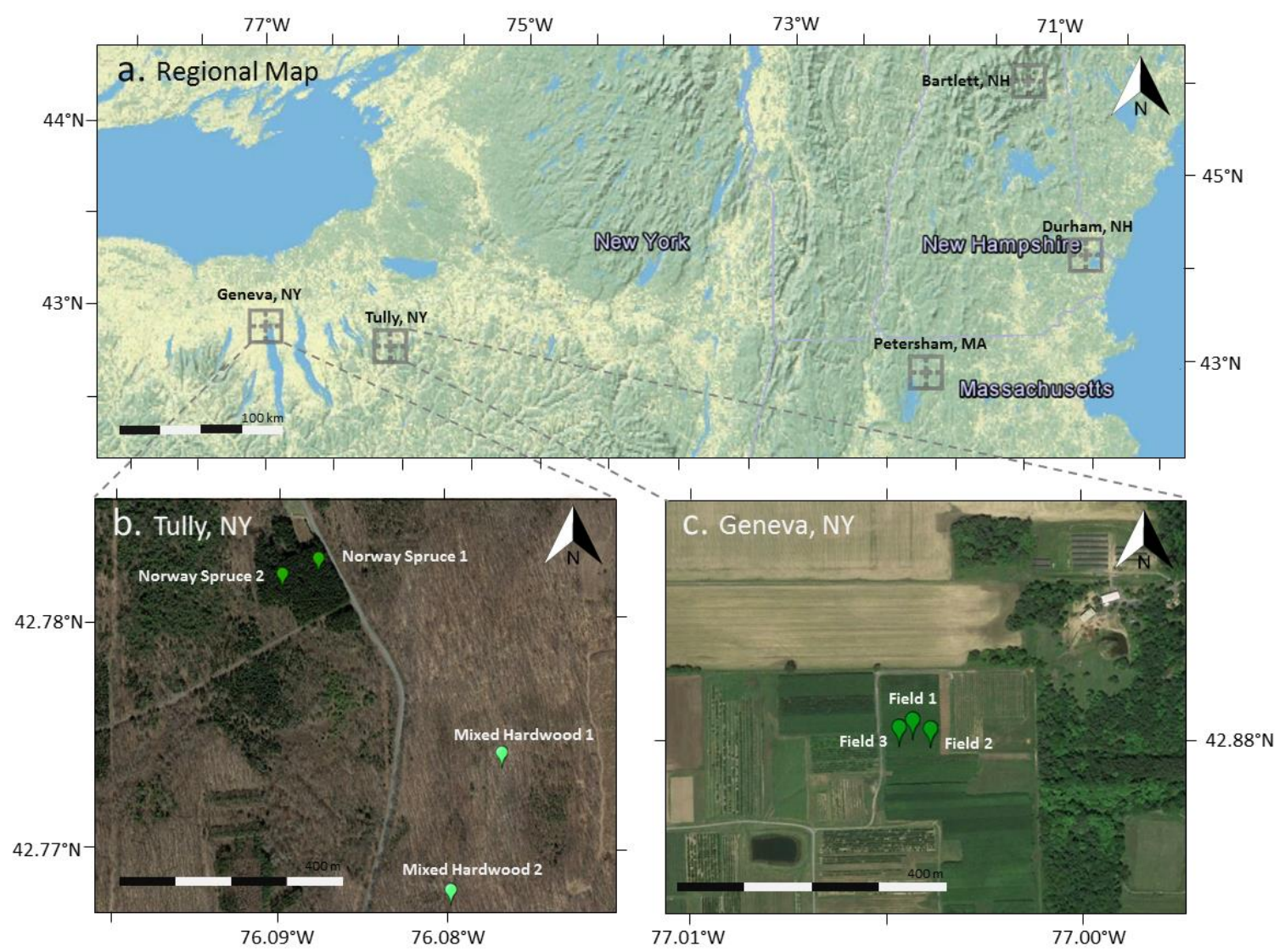

Figure 3. Inset A depicts a regional map of the sites measured in this study. Inset B highlights sites of UAV flights in Tully, NY. Inset C highlights sites of UAV flights in Geneva, NY. Inset A is sourced from 2018 NOAA Imagery. Insets B and C are sourced from Google Earth satellite imagery, April and July 1995 respectively.

Table 1. The locations, typical July temperatures and precipitation, and dominant vegetation of the five study sites.

\begin{tabular}{|c|c|c|c|c|c|}
\hline Objective & Site & Lat $\left({ }^{\circ}\right)$ & Lon $\left(^{\circ}\right)$ & $\begin{array}{c}\text { Canopy Height } \\
\text { (avg, m) }\end{array}$ & Dominant Land Cover \\
\hline $\begin{array}{c}\text { Targeted Flights } \\
U A V, \text { Satellite }\end{array}$ & $\begin{array}{c}\text { Tully, NY } \\
\text { Mixed Forest }\end{array}$ & 42.733 & -76.081 & 23 & Acer saccharum, Fagus grandifolia \\
\hline $\begin{array}{l}\text { Comparative } \\
\text { Tower, Satellite }\end{array}$ & $\begin{array}{c}\text { Durham, } \mathrm{NH}^{\dagger} \\
\text { Mixed Forest }\end{array}$ & 43.111 & -70.955 & 17 & $\begin{array}{l}\text { Quercus rubra, Pinus strobus, } \\
\text { Acer rubrum, Carya ovata, Quercus alba }\end{array}$ \\
\hline $\begin{array}{l}\text { Comparative } \\
\text { Tower, Satellite }\end{array}$ & $\begin{array}{l}\text { Bartlett, } \mathrm{NH}^{\ddagger} \\
\text { Mixed Forest }\end{array}$ & 44.065 & -71.289 & 21 & $\begin{array}{l}\text { F. grandifolia, Picea rubens, A. rubrum, } \\
\text { Abies balsamea, Tsuga canadensis, } \\
\text { A. saccharum, Betula alleghaniensis }\end{array}$ \\
\hline $\begin{array}{l}\text { Comparative, } \\
\text { Tower, Satellite }\end{array}$ & $\begin{array}{l}\text { Petersham, MA } \S \\
\text { Mixed Forest }\end{array}$ & 42.535 & -72.190 & 16 & $\begin{array}{l}\text { Q. rubra, } P . \text { strobus, A. rubrum, } \\
\text { T. canadensis }\end{array}$ \\
\hline $\begin{array}{l}\text { Validation, } \\
U A V / \text { Tower }\end{array}$ & $\begin{array}{l}\text { Geneva, NY } \\
\text { Cropped Willow }\end{array}$ & 42.883 & -77.004 & 3 & Salix spp. \\
\hline $\begin{array}{c}\text { Land Use Flight, } \\
U A V\end{array}$ & $\begin{array}{c}\text { Tully, NY } \\
\text { Spruce Stand }\end{array}$ & 42.733 & -76.081 & 23 & Picea abies \\
\hline
\end{tabular}

\subsubsection{Targeted UAV Measurements over Mixed Hardwood Forest}

The UAV made five flights at Tully, NY over deciduous hardwood forest, one at local solar noon, two flights one and two hours prior to local solar noon, and two flights one and two hours 
after local solar noon on 27 July 2016 (Supplementary Table S1). In each flight, the UAV followed a pre-programmed course to the designated coordinates and altitude in approximately one minute. The UAV then held its position until the battery was nearly exhausted, approximately ten minutes, before returning to the staging area. Conditions on 27 July 2016 were clear, with minimal cloud cover moving in around local solar noon, and local air quality index less than 50 for both particulate matter and ozone [38].

\subsubsection{Comparative Tower and Satellite Measurements over Mixed Hardwood Forest}

Tower albedo measurements for the three other mixed hardwood forest sites used here were made in July 2014 and 2015 between 20 July and 24 July. Only measurements taken between $2.5 \mathrm{~h}$ prior to and $2.5 \mathrm{~h}$ post solar noon were used, to better match UAV data. Readings at Durham were taken every $30 \mathrm{~s}$, Bartlett readings were taken every $5 \mathrm{~s}$, and Petersham measurements were taken every $1 \mathrm{~s}$. Half-hour averages of these measurements were used. For each individual day, the sum of all half-hourly reflected radiation values was divided by the sum of incoming radiation values to get a flux-weighted albedo value for the day.

Durham, NH, USA albedo was measured by a Kipp and Zonen CMA6 (effective half field of view $=81^{\circ}$ ) placed on a $4.5 \mathrm{~m}$ leveling boom extended from $25 \mathrm{~m}$ up a $30 \mathrm{~m}$ tower [27]. Albedo at Bartlett, $\mathrm{NH}$, USA was collected using two Kipp and Zonen CMP3 pyranometers (effective half field of view $=81^{\circ}$ ) placed $23.8 \mathrm{~m}$ and $25 \mathrm{~m}$ up a $30 \mathrm{~m}$ tower, facing downwards on a $3 \mathrm{~m}$ leveling boom and upwards on a $1 \mathrm{~m}$ boom respectively [36]. Albedo values at Petersham, MA, USA were taken using a CNR-4 Kipp \& Zonen 4-channel net radiometer mounted on a $3 \mathrm{~m}$ boom extending south from a $40 \mathrm{~m}$ tower (Effective Field of View $81^{\circ}$ ) $[39,40]$.

Satellite albedo measurements for Tully mixed hardwood forest and the three comparative forest sites were extracted from the MODIS bidirectional reflectance distribution function albedo product (MCD43A3: MODIS/Terra and Aqua Albedo Daily L3 Global $500 \mathrm{~m}$ SIN Grid V006) [41], for DOY 201-215, from 2014, 2015, and 2016. Pixels marked as low-quality in the MODIS quality control data were removed from the analysis. Due to these conditions, only data from 2015 and 2016 was available for Bartlett, NH and Durham, NH. Satellite albedo at the UAV flight site at Tully were extracted from four pixels, a square half kilometer each (Supplementary Table S2). Satellite albedo for the tower sites were pulled from single pixels (Supplementary Table S3). Satellite shortwave albedo at solar noon were converted from black-sky and white-sky albedo to blue-sky using a standard conversion formula $[42,43]$. Aerosol optical depth (AOD; unitless) was assumed to be 0.2 , although a realistic range of environmental depths from $0.1-0.5$ was also examined to test sensitivity (Supplementary Table S4). The sensitivity analysis showed that the low and high estimates were not significantly different from 0.2 for any of the examined satellite datasets, and so the 0.2 AOD value was used for the final comparison (NASA, 2016).

\subsubsection{Validation Measurements Comparing Simultaneous UAV and Tower Data}

Validation flights were conducted on 31 July 2017 over a cropped willow field in Geneva, NY to compare UAV-measured albedo to tower-based measurements. Fixed tower data was collected from a mounted Kipp and Zonen CMA6 albedometer fixed at $8 \mathrm{~m}$ on a $30 \mathrm{~cm}$ boom. The UAV was first positioned one meter due west of the mounted albedometer, maintaining a height of $8 \mathrm{~m}$ (Supplementary Table S1). This first flight took place $30 \mathrm{~min}$ prior to local solar noon; two subsequent flights took place $15 \mathrm{~min}$ prior, and $30 \mathrm{~min}$ post local solar noon. For the second and third flight the UAV was positioned at the same height, $24 \mathrm{~m}$ west and $29 \mathrm{~m}$ east of the tower, which remained fixed at the center point. All flights took place on a clear day with the local air quality index less than 50 for ozone and below 100 for particulate matter (unitless) [38]. Partial cloud cover appeared towards the end of the third validation flight. 


\subsubsection{UAV Measurements Comparing Albedo across Multiple Scenarios of Land Use}

Follow-up flights took place a year later, on 30 July 2017. First and second flights on 30 July were made at Tully, NY over a Norway spruce (Picea abies) plantation, over two neighboring locations within the same spruce plantation, at 0.5 and $1 \mathrm{~h}$ post local solar noon, respectively. A second and third flight revisited the same deciduous hardwood forest site as was measured above, as well as a second deciduous hardwood site within the same forest block, at $1.5 \mathrm{~h}$ post solar noon and $2 \mathrm{~h}$ post local solar noon. 30 July 2017 was completely clear with no clouds; local air quality index was less than 50 for both particulate matter and ozone [38]. Finally, willow albedo data as collected above was used alongside the spruce and deciduous forest data to compare albedo over three different land uses.

\subsection{Data Processing and Analysis}

Outliers were removed where measured incoming solar radiation was less than $60 \%$ of predicted solar insolation.

$$
\text { Predicted Solar Insolation }=\text { Solar Constant } * \cos \left(\frac{\text { Zenith Angle } * \pi}{180}\right)
$$

This removed values representing $18 \%, 48 \%, 57 \%$, and $46 \%$ of the original data, at Tully, Durham, Bartlett, and Petersham, respectively (the multiple day measurements at the last three sites resulted in there having been more clouded days to remove). We also examined albedo at solar noon, as solar noon measurements are more comparable to solar noon-approximated satellite values. For both UAV and tower data, albedo at solar noon was defined as all measurements within one hour of solar noon at that site on the day of the measurement.

Data were analyzed in R version 3.2.1 [44]. We conducted a Type II ANOVA [45] and the Tukey HSD test from stats v3.4.1., to compare site level differences across both in-situ and satellite measurements; Anova residuals were normally distributed. We used the $\mathrm{R} t$-test from stats v3.4.1. to conduct a Student $t$-test to compare in-situ and satellite measurements; albedo was transformed with a negative reciprocal 7 th power transformation.

\section{Results}

\subsection{Targeted UAV Measurements over Mixed Hardwood Forest}

We examined the temporal consistency of albedo estimates across flights and years in a series of flights over a mixed hardwood forest in Tully, NY. The series of five flights spaced hourly around local solar noon measured a summer forest albedo of $0.145 \pm 0.005 \mathrm{SD}, n=5$, and ranged from 0.140 to 0.146 . The mixed hardwood albedo at solar noon, 0.145 , was the same as the mean and was consistent with albedo values recorded over the course of the day.

\subsection{Comparative Tower and Satellite Measurements over Mixed Hardwood Forest}

UAV albedo values were compared to tower measurements from three similar mixed northern hardwood forests (Figure 4). 


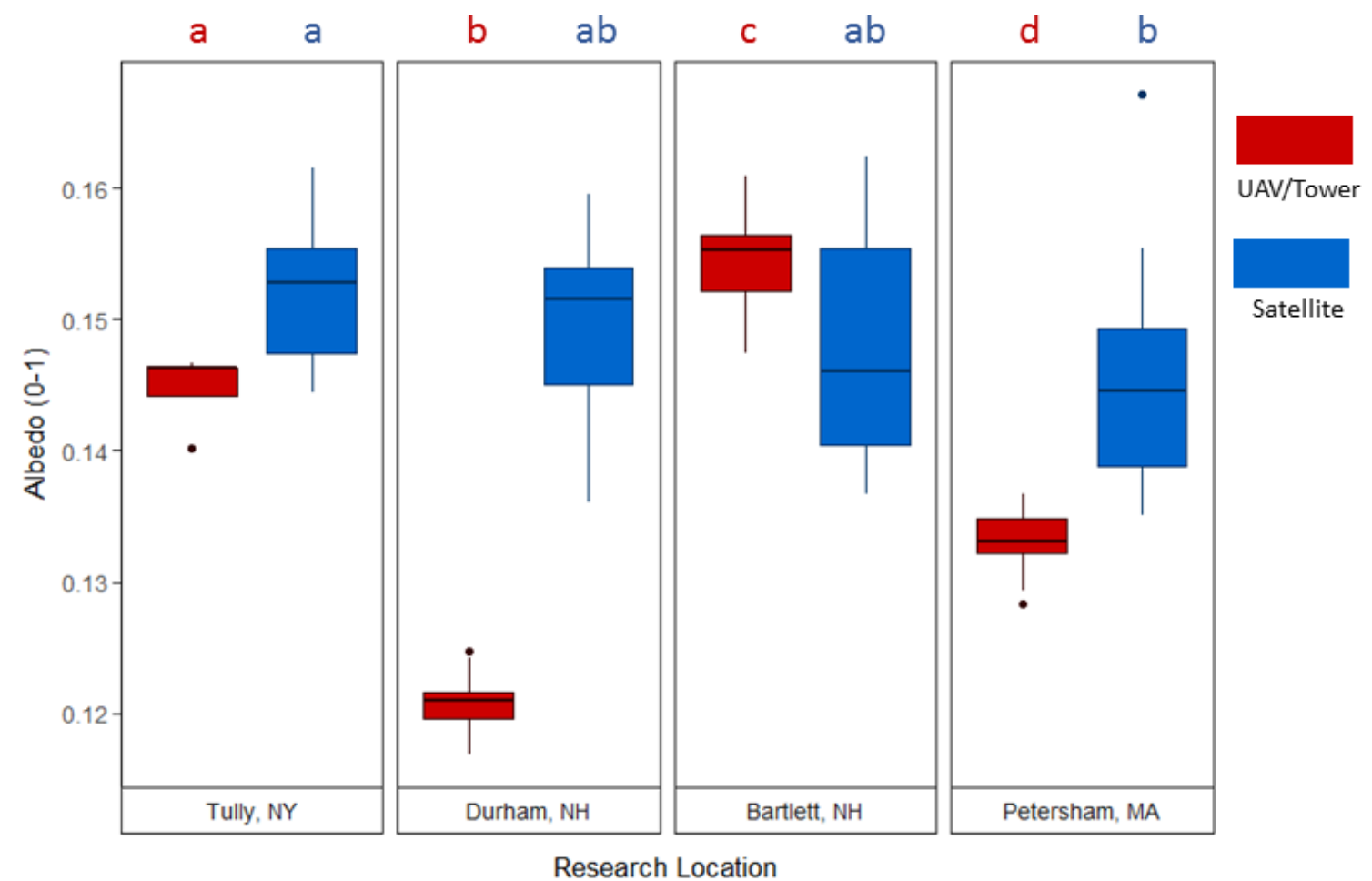

Figure 4. Boxplots showing albedo over mixed temperate forest as measured by UAV (red) and MODIS satellite data (blue) in (a) Tully, NY and by fixed towers (red, $0.145 \pm 0.003 \mathrm{SD}, n=5$ ) and MODIS satellite data (blue, $0.152 \pm 0.005 \mathrm{SD}, n=70$ ) at (b) Durham (red, $0.121 \pm 0.015 \mathrm{SD}, n=12$; blue, $0.151 \pm 0.006 \mathrm{SD}, n=23$ ), (c) Bartlett (red, $0.155 \pm 0.008 \mathrm{SD}, n=13$; blue, $0.148 \pm 0.008 \mathrm{SD}, n=18$ ), and (d) Petersham (red, $0.133 \pm 0.009$ SD, $n=12$; blue, $0.145 \pm 0.008$ SD, $n=18$ ). Box and whisker plots show medians, data quartiles, and outliers. Letters over tower and satellites represent significant differences within UAV and tower measurements at Tully, Durham, Bartlett, and Petersham (calculated by ANOVA, Tukey HSD), and within satellite measurements at each of the same (calculated by ANOVA, Tukey HSD).

The average summer albedo at the Durham, NH tower was lower than UAV measurements by 0.02 , while albedo at the Bartlett tower was higher by 0.02. Albedo at the Petersham, MA tower was lower by 0.01 . While differences between each of the four sites were small, they were statistically significant, showing clear across-site heterogeneity (Type II Anova, $\mathrm{df}=3, F$ value $=271, p<0.001$ ). At all sites, albedo at solar noon was within 0.01 units of the five hour albedo, and was not significantly different from the full albedo. Overall, all sites fell within the needed accuracy of 0.02-0.05 albedo units of each other. In comparison, satellite albedo data varied little across sites, with only Tully and Petersham showing a significant difference of less than 0.01 units, showing very little across site heterogeneity.

We then compared the in-situ UAV and tower measurements to albedo measurements made by satellite. At the Tully site, MODIS average albedo was slightly higher than in-situ, UAV-measured albedo (Student $t$-test: $\mathrm{df}=8.05, t=-6.34, p<0.001$ ). In Durham, satellite albedo was also significantly greater than in-situ, tower-measured albedo values (Student $t$-test: $\mathrm{df}=-15.3, t=23.1, p<0.001$ ). Likewise, Petersham satellite albedo was significantly greater than the in-situ measurements by tower (Student $t$-test: $\mathrm{df}=21.2, t=-6.03, p<0.001$ ). However, at Bartlett, the average albedo value measured by satellite was significantly less than the average tower albedo (Student $t$-test: $\mathrm{df}=18.0, t=-4.60$, $p<0.001)$. Both UAV showed similar consistency ( 0.01 albedo units lower) with satellite measurements as tower measurements had with respective satellite measurements (Durham: 0.03 lower, Bartlett: 0.01 higher, Petersham: 0.01 higher). Overall, the coefficient of variation across all summer UAV 
albedo measurements made over mixed hardwood forest at Tully $(2.1 \%)$ was similar to the variability observed at the in-situ estimates made by towers (Durham: 1.9\%, Bartlett: 2.7\%, Petersham: 1.9\%).

\subsection{Validation Measurements comparing Simultaneous $U A V$ and Tower Data}

We compared albedo measurements taken by tower and UAV approaches, over the same field of willow biofuels. Initial side by side flights by both methods produced closely matched albedo estimates (Figure 5).

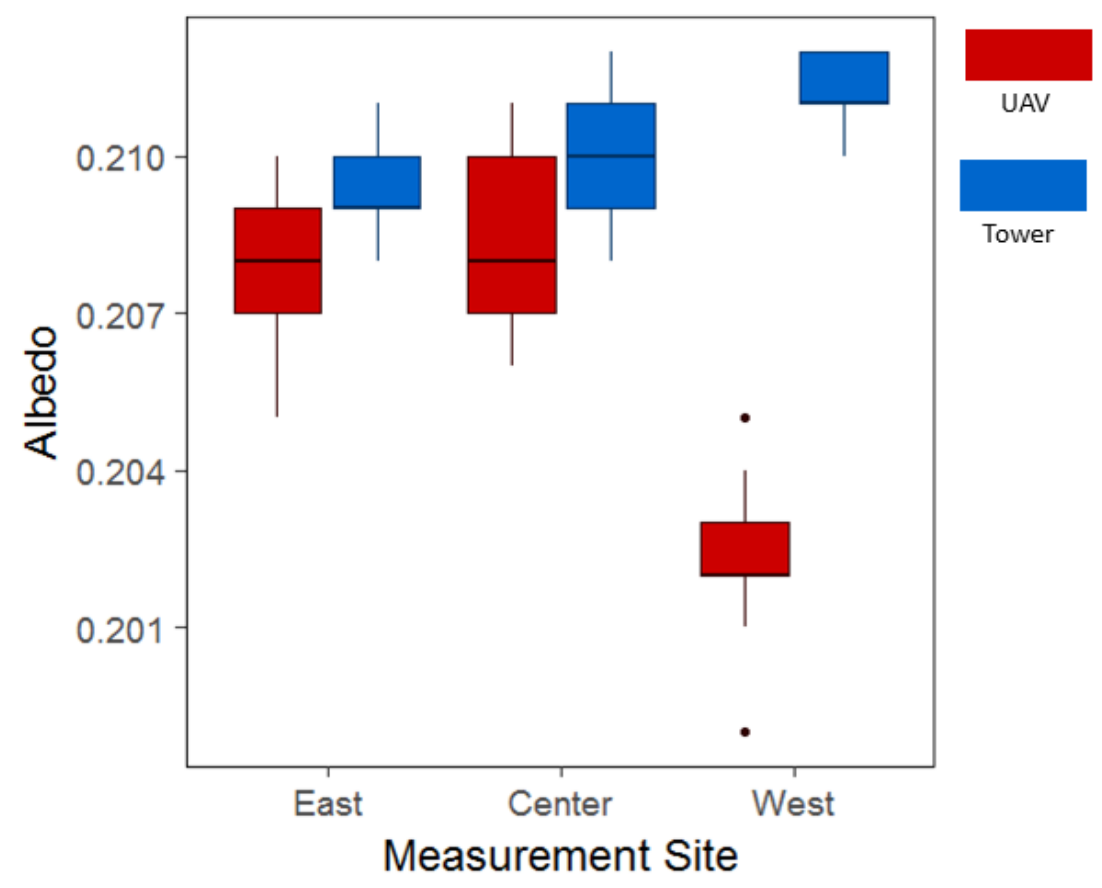

Figure 5. Albedo was measured by UAV over a willow biofuel field at three sites: immediately adjacent to a fixed tower $(0.208 \pm 0.001 \mathrm{SD}, n=19), 24$ meters east of the tower $(0.208 \pm 0.002 \mathrm{SD}, n=23)$, and $24 \mathrm{~m}$ west of the tower $(0.202 \pm 0.002 \mathrm{SD}, n=21)$. Tower measurements were taken simultaneously with each flight from a fixed location at center $(0.209 \pm 0.001 \mathrm{SD}, n=19 ; 0.210 \pm 0.001 \mathrm{SD}, n=23$; $0.211 \pm 0.001 \mathrm{SD}, n=21)$. UAV measurements are depicted in red, while paired, simultaneous fixed tower measurements are depicted in blue. Box and whisker plots show medians, data quartiles, and outliers.

Measurements were repeated over the same willow field, using the UAV in flights $24 \mathrm{~m}$ west and then 29 m east of the tower. All UAV-derived willow albedo measurements were well within \pm 0.01 of each other, but there was slightly greater correspondence between the side-by-side measurements and measurements made over willow a distance from the tower. UAV albedo tended to have greater variability than tower albedo, regardless of the sub-site, although overall variance was low.

\subsection{UAV Measurements Demonstrating Albedo across Multiple Scenarios of Land Use}

Three land use types were examined in parallel: surveys of monoculture of Norway spruce (Figure 6) measured an albedo of 0.0743 and 0.0824 . Two flights resurveyed the same forest site and an adjacent point, as described above, with albedo of 0.149 and 0.154 . Three flights over a cropped willow field, as described above, were measured at $0.208,0.208$, and 0.202 albedo. The variation across sites was an order of magnitude less than the variation across the different land uses. 


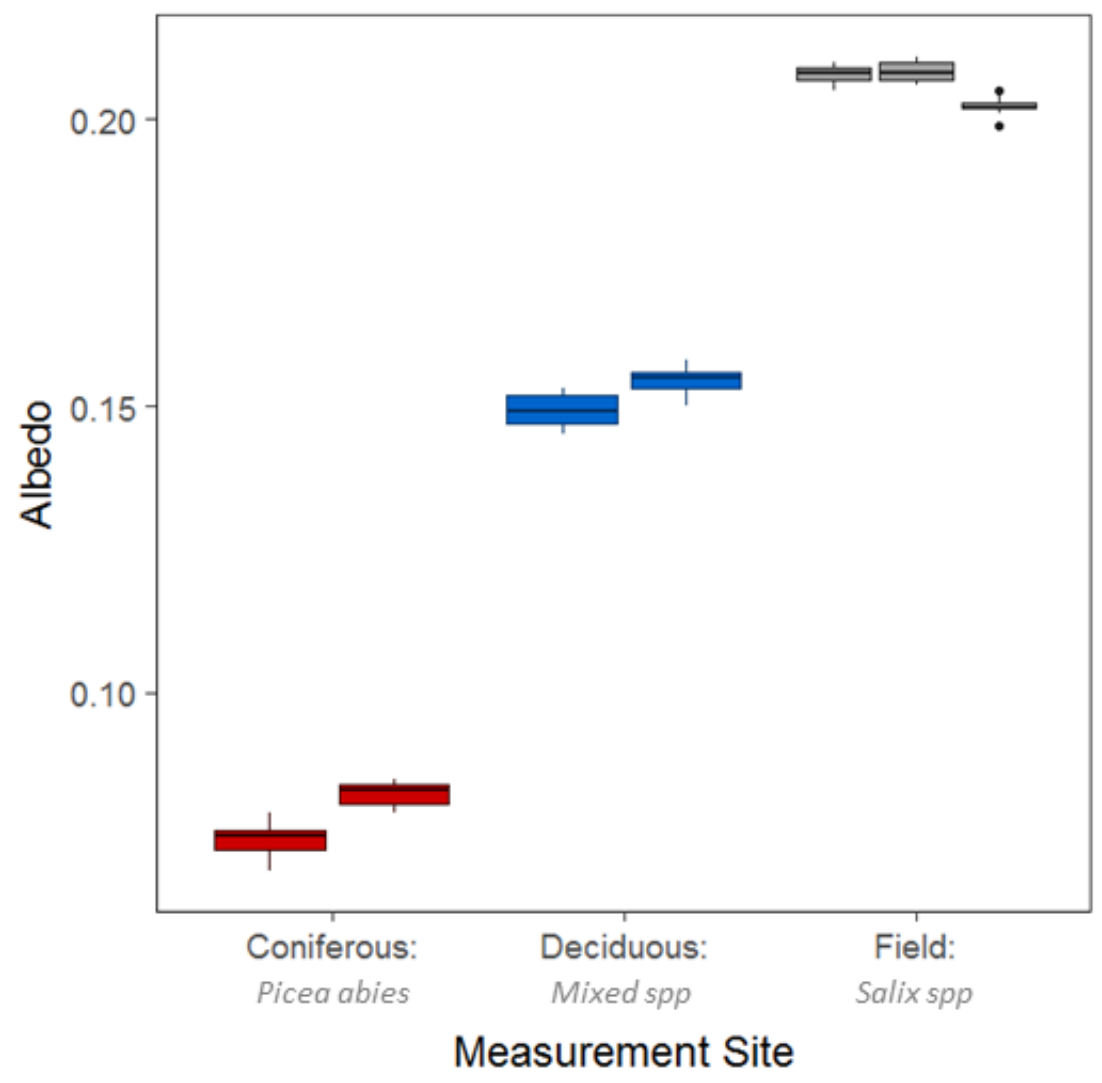

Figure 6. Albedo measured by UAV for three different land use types: two adjacent coniferous forest sites at Tully, NY $(0.074 \pm 0.002, n=24 ; 0.082 \pm 0.002, n=23)$ (red), two adjacent mixed northern hardwood forest sites at Tully, NY $(0.149 \pm 0.002, n=22 ; 0.154 \pm 0.002, n=23)$ (blue), and three adjacent cropped willow sites at Geneva, NY $(0.208 \pm 0.001, n=19 ; 0.208 \pm 0.002, n=23 ; 0.202 \pm 0.002, n=21)$ (gray). Error bars represent the variance, reported as standard error, within each flight.

\section{Discussion}

Evaluation of earth system models requires surface albedo estimates with an absolute accuracy of between 0.02-0.05 units of albedo [24,42,46]. In this study, UAV flights over a mixed northern hardwood forest produced measurements within 0.01 units of each other across five flights and five hours. This albedo fell well within the range of site variation in albedo for fixed tower measurements of mixed forest albedo in Bartlett, NH; Durham, NH; and Petersham, MA, differing by no more than 0.02 units despite small cross-site differences in field of view, topography, and species composition. The tight grouping of UAV and tower estimates over a common, well-surveyed land use type supports the idea that this methodology will be able to provide accurate albedo measurements over land use types that have been poorly surveyed by conventional methods. Measurements made over a Norway spruce monoculture and cropped willow field show that the UAV easily distinguishes between land use types across multiple flights. These flights demonstrate how UAV may be used to sample sites that are not well captured by either satellite or tower measurements due to their small footprint or high rate of turnover for harvesting.

Although ground measurements (UAV and tower) were tightly grouped within a small range of albedo, each site was significantly different from the others, indicating site to site variation likely caused by species, land use, and topographic differences. This variability was poorly captured by satellite measurements, which were more tightly grouped and generally not significantly different from each other. Due to this, satellite data poorly estimated variation on the ground; UAV and tower data were generally lower than satellite data by 6 to $16 \%$, although Bartlett forest reported $9 \%$ higher albedo than the satellite. UAV data did not differ from tower data in this way. This finding provides 
additional support for the use of ground measurements, such as can be obtained by UAV, to validate satellite measurements and refine model predictions. Satellites have a larger and differently distributed field of view which may be confounded by different land use types at the pixel boundaries [4,24]. UAV can capture albedo with greater precision, and with the flexibility to take fine-scale measurements across the entire landscape.

Certain caveats of this method should be considered; uneven cloud cover means that a homogenous down-welling flux of incoming solar radiation cannot be assumed over the UAV's entire flight path. All flights in this study had to be recorded on days with no to very minimal cloud cover. UAVs must be flown such that unaided line of site is maintained, which can limit the range and altitude possible for flights over high canopy (Supplementary Table S5). Finally, continuous albedo measurements over the course of an entire day would be dependent either on the capacity to make many serial flights over the time horizon desired.

Satellites are often insufficient to capture the fine-scale landscape heterogeneity caused by local variation in canopy density, vegetative community, terrain, and other local scale properties [4,24,42]. Fine-scale point measurements, however, often lack the range needed to assess these properties on a global scale [3]. It is our belief that using UAVs to measure albedo will improve our ability to determine sources of variability in albedo measurements. Payload mass reduction through a split upwards and downward-facing sensor widens the range of UAVs available for these types of measurements and maximizes flight time (Table 2). The method described here provides a simple method of albedo assessment accessible to the typical researcher.

Table 2. Payload capacity and expected payload for common UAVs and commercially available albedo equipment.

\begin{tabular}{cccc}
\hline UAV & Payload Capacity (g) & Payload & Mass (g) \\
\hline DJI Phantom 3 & 300 & CMP3 & 300 \\
Sky Hero Spyder 700 & 1600 & Datalogger & 200 \\
Freefly Systems ALTA & 6800 & Gimbal * & $200-600$ \\
DJI Spreading Wings & & & \\
S900 Professional & 8200 & & \\
Hexacopter & & & \\
\hline
\end{tabular}

* Based on MK HiSight SLR1 and Gaui Crane Gimbal.

\section{Conclusions}

UAVs offer an opportunity to make flexible, efficient radiation measurements at many locations and scales. Here, we validated a method of measuring albedo by UAV while minimizing payload and technical requirements. We found that UAVs provided stable albedo measurements across multiple flights over a mixed hardwood forest, with results that were well within the range of tower-estimated albedo at similar forested sites. Simultaneous albedo estimates by UAV and a fixed tower at the same site showed that the two methods produced near identical results. Finally, we demonstrated that in-situ albedo measurements (tower and UAV) capture more site-to-site variation in albedo than satellite measurements. Overall, we show that UAVs produce reliable, consistent albedo measurements that can capture crucial surface heterogeneity, clearly distinguishing between different land uses.

Supplementary Materials: The following are available online at http:/ /www.mdpi.com/2072-4292/10/8/1303/ s1, Table S1: Dates, times, and locations of described UAV flights, Table S2: Latitude and longitude of UAV satellite pixels Table S3: Latitude and longitude of tower satellite pixels, Table S4: Blue sky albedo estimates for sites in Tully, NY. Table S5: Current FAA requirements for UAV research within the United States.

Author Contributions: Conceptualization, C.R.L.; UAV and Satellite Dataset, C.R.L.; Harvard and Bartlett Forest Dataset, A.D.R.; Durham Forest Dataset, E.B.; Validation and Analysis, C.R.L.; Writing-Original Draft Preparation, C.R.L.; Writing-Review \& Editing, C.R.L., E.B., and A.D.R. 
Funding: This research was funded by the David R Atkinson Center for a Sustainable Future, through the Academic Venture Fund program. Harvard and Bartlett Forest measurements were funded by the National Science Foundation through the LTER program, which has supported research at Harvard Forest (DEB-1237491) and Bartlett Experimental Forest (DEB-1114804).

Acknowledgments: Timothy Fahey was the primary investigator on this grant, and is particularly thanked for his support. The authors would also like to extend sincere thanks and appreciation to Martin LaChance of UAV Imaging Systems for his expertise and hard work in realizing this project.

Conflicts of Interest: The authors declare no conflict of interest.

\section{References}

1. Latifi, H.; Galos, B. Remote sensing-supported vegetation parameters for regional climate models: A brief review. IForest 2010, 3, 98-101. [CrossRef]

2. Pfeifer, M.; Disney, M.; Quaife, T.; Marchant, R. Terrestrial ecosystems from space: A review of earth observation products for macroecology applications. Glob. Ecol. Biogeogr. 2012, 21, 603-624. [CrossRef]

3. Pan, S.; Tian, H.; Dangal, S.R.S.; Ouyang, Z.; Tao, B.; Ren, W.; Lu, C.; Running, S. Modeling and monitoring terrestrial primary production in a changing global environment: Toward a multiscale synthesis of observation and simulation. Adv. Meteorol. 2014, 2014. [CrossRef]

4. Cescatti, A.; Marcolla, B.; Santhana Vannan, S.K.; Pan, J.Y.; Roman, M.O.; Yang, X.; Ciais, P.; Cook, R.B.; Law, B.E.; Matteucci, G.; et al. Intercomparison of MODIS albedo retrievals and in situ measurements across the global FLUXNET network. Remote Sens. Environ. 2012, 121, 323-334. [CrossRef]

5. Randerson, J.T.; Liu, H.; Flanner, M.G.; Chambers, S.D.; Jin, Y.; Hess, P.G.; Pfister, G.; Mack, M.C.; Treseder, K.K.; Welp, L.R.; et al. The impact of boreal forest fire on climate warming. Science 2006, 314, 1130-1132. [CrossRef] [PubMed]

6. Otto, J.; Berveiller, D.; Bréon, F.M.; Delpierre, N.; Geppert, G.; Granier, A.; Jans, W.; Knohl, A.; Kuusk, A.; Longdoz, B.; et al. Forest summer albedo is sensitive to species and thinning: How should we account for this in Earth system models? Biogeosciences 2014, 11, 2411-2427. [CrossRef]

7. Wang, Z.; Erb, A.M.; Schaaf, C.B.; Sun, Q.; Liu, Y.; Yang, Y.; Shuai, Y.; Casey, K.A.; Román, M.O. Early spring post-fire snow albedo dynamics in high latitude boreal forests using Landsat-8 OLI data. Remote Sens. Environ. 2016, 185, 71-83. [CrossRef] [PubMed]

8. Jackson, R.B.; Randerson, J.T.; Canadell, J.G.; Anderson, R.G.; Avissar, R.; Baldocchi, D.D.; Bonan, G.B.; Caldeira, K.; Diffenbaugh, N.S.; Field, C.B.; et al. Protecting climate with forests. Environ. Res. Lett. 2008, 3, 1-5. [CrossRef]

9. Kirschbaum, M.U.F.; Whitehead, D.; Dean, S.M.; Beets, P.N.; Shepherd, J.D.; Ausseil, A.-G.E. Implications of albedo changes following afforestation on the benefits of forests as carbon sinks. Biogeosciences 2011, 8 , 3687-3696. [CrossRef]

10. Betts, R.; Falloon, P.D.; Goldewijk, K.K.; Ramankutty, N. Biogeophysical effects of land use on climate: Model simulations of radiative forcing and large-scale temperature change. Agric. For. Meteorol. 2007, 142, 216-233. [CrossRef]

11. Betts, R. Offset of the potential carbon sink from boreal forestation by decreases in surface albedo. Nature 2000, 408, 187-190. [CrossRef] [PubMed]

12. Wang, Z.; Zeng, X. Evaluation of snow albedo in land models for weather and climate studies. J. Appl. Meteorol. Climatol. 2010, 49, 363-380. [CrossRef]

13. Flanner, M.G.; Zender, C.S. Linking snowpack microphysics and albedo evolution. J. Geophys. Res. 2006, 111, 2156-2202. [CrossRef]

14. Bonan, G.B. Forests and climate change: Forcings, feedbacks, and the climate benefits of forests. Science 2008, 320, 1444-1449. [CrossRef] [PubMed]

15. Bright, R.M. Metrics for biogeophysical climate forcings from land use and land cover changes (LULCC) and their inclusion in Life Cycle Assessment (LCA): A critical review. Environ. Sci. Technol. 2015, 49, 3291-3303. [CrossRef] [PubMed]

16. Zhao, K.; Jackson, R.B. Biophysical forcings of land-use changes from potential forestry activities in North America. Ecol. Monogr. 2014, 84, 329-353. [CrossRef]

17. Chen, L.; Dirmeyer, P.A. Adapting observationally based metrics of biogeophysical feedbacks from land cover/land use change to climate modeling. Environ. Res. Lett. 2016, 11. [CrossRef] 
18. Burakowski, E.; Tawfik, A.; Ouimette, A.; Lepine, L.; Novick, K.; Ollinger, S.; Zarzycki, C.; Bonan, G. The role of surface roughness, albedo, and Bowen ratio on ecosystem energy balance in the Eastern United States. Agric. For. Meteorol. 2018, 249, 367-376. [CrossRef]

19. Lee, X.; Goulden, M.L.; Hollinger, D.Y.; Barr, A.; Black, T.A.; Bohrer, G.; Bracho, R.; Drake, B.; Goldstein, A.; $\mathrm{Gu}, \mathrm{L}$; et al. Observed increase in local cooling effect of deforestation at higher latitudes. Nature 2011, 479, 384-387. [CrossRef] [PubMed]

20. Lutz, D.A.; Burakowski, E.A.; Murphy, M.B.; Borsuk, M.E.; Niemiec, R.M.; Howarth, R.B. Tradeoffs between three forest ecosystem services across the state of New Hampshire, USA: Timber, carbon, and albedo. Ecol. Appl. 2016, 26, 146-161. [CrossRef] [PubMed]

21. Barnes, C.A.; Roy, D.P. Radiative forcing over the conterminous United States due to contemporary land cover land use albedo change. Geophys. Res. Lett. 2008, 35, 1-6. [CrossRef]

22. Montenegro, A.; Eby, M.; Mu, Q.; Mulligan, M.; Weaver, A.J.; Wiebe, E.C.; Zhao, M. The net carbon drawdown of small scale afforestation from satellite observations. Glob. Planet. Chang. 2009, 69, 195-204. [CrossRef]

23. Campagnolo, M.L.; Sun, Q.; Liu, Y.; Schaaf, C.; Wang, Z.; Román, M.O. Estimating the effective spatial resolution of the operational BRDF, albedo, and nadir reflectance products from MODIS and VIIRS. Remote Sens. Environ. 2016, 175, 52-64. [CrossRef]

24. Roman, M.O.; Schaaf, C.; Woodcock, C.E.; Strahler, A.H.; Yang, X.; Braswell, R.H.; Curtis, P.S.; Davis, K.J.; Dragoni, D.; Goulden, M.L.; et al. The MODIS (Collection V005) BRDF/albedo product: Assessment of spatial representativeness over forested landscapes. Remote Sens. Environ. 2009, 113, 2476-2498. [CrossRef]

25. Franch, B.; Vermote, E.F.; Claverie, M. Intercomparison of Landsat albedo retrieval techniques and evaluation against in situ measurements across the US SURFRAD network. Remote Sens. Environ. 2014, 152, 627-637. [CrossRef]

26. Roy, D.P.; Zhang, H.K.; Ju, J.; Gomez-Dans, J.L.; Lewis, P.E.; Schaaf, C.; Sun, Q.; Li, J.; Huang, H.; Kovalskyy, V. A general method to normalize Landsat reflectance data to nadir BRDF adjusted reflectance. Remote Sens. Environ. 2016, 176, 255-271. [CrossRef]

27. Burakowski, E.; Ollinger, S.V.; Lepine, L.; Schaaf, C.; Wang, Z.; Dibb, J.E.; Hollinger, D.Y.; Kim, J.; Erb, A.; Martin, M. Spatial scaling of reflectance and surface albedo over a mixed-use, temperate forest landscape during snow-covered periods. Remote Sens. Environ. 2015, 158, 465-477. [CrossRef]

28. Adolph, A.C.; Albert, M.R.; Lazarcik, J.; Dibb, J.E.; Amante, J.M.; Price, A. Dominance of grain size impacts on seasonal snow albedo at open sites in New Hampshire. J. Geophys. Res. 2017, 122, 121-139. [CrossRef]

29. Warren, S.G.; Wiscombe, W.J. A Model for the Spectral Albedo of Snow. II: Snow Containing Atmospheric Aerosols. J. Atmos. Sci. 1980, 37, 2734-2745. [CrossRef]

30. Anderson, K.; Gaston, K.J. Lightweight unmanned aerial vehicles will revolutionize spatial ecology. Front. Ecol. Environ. 2013, 11, 138-146. [CrossRef]

31. Cruzan, M.B.; Weinstein, B.G.; Grasty, M.R.; Kohrn, B.F.; Hendrickson, E.C.; Arredondo, T.M.; Thompson, P.G. Small Unmanned Aerial Vehicles (Micro-UAVs, Drones) in Plant Ecology. Appl. Plant Sci. 2016, 4. [CrossRef] [PubMed]

32. U.S. Department of Transportation Federal Aviation Administration (FAA). Air Traffic Organization Policy, Order JO 7110.65V; FAA: Washington, DC, USA, 2017.

33. Ramana, M.V.; Ramanathan, V.; Kim, D.; Roberts, G.C.; Corrigan, C.E. Albedo, atmospheric solar absorption and heating rate measurements with stacked UAVs. Q. J. R. Meteorol. Soc. 2007, 133, 937-948. [CrossRef]

34. Schneider, C.; Truffer, M.; Michael Shea, J.; Hubbard, A.; Ryan, J.C.; Box, J.E.; Brough, S.; Cameron, K.; Cook, J.M.; Cooper, M.; et al. Derivation of High Spatial Resolution Albedo from UAV Digital Imagery: Application over the Greenland Ice Sheet. Front. Earth Sci. 2017, 5, 1-13. [CrossRef]

35. Weiser, U.; Olefs, M.; Schöner, W.; Weyss, G.; Hynek, B. Correction of broadband snow albedo measurements affected by unknown slope and sensor tilts. Cryosphere 2016, 10, 775-790. [CrossRef]

36. Jenkins, J.P.; Richardson, A.D.; Braswell, B.H.; Ollinger, S.V.; Hollinger, D.Y.; Smith, M.L. Refining light-use efficiency calculations for a deciduous forest canopy using simultaneous tower-based carbon flux and radiometric measurements. Agric. For. Meteorol. 2007, 143, 64-79. [CrossRef]

37. Wang, Z.; Schaaf, C.; Strahler, A.H.; Chopping, M.J.; Román, M.O.; Shuai, Y.; Woodcock, C.E.; Hollinger, D.Y.; Fitzjarrald, D.R. Evaluation of MODIS albedo product (MCD43A) over grassland, agriculture and forest surface types during dormant and snow-covered periods. Remote Sens. Environ. 2014, 140, 60-77. [CrossRef] 
38. Environmental Protection Agency AirNow. Available online: https://www.airnow.gov/index.cfm?action= airnow.mapsarchivecalendar (accessed on 25 October 2016).

39. Richardson, A.D. Radiometric and Meteorological Data from Harvard Forest Barn Tower Since 2011. Available online: http:/ / harvardforest.fas.harvard.edu:8080/exist/apps / datasets/showData.html?id=hf249 (accessed on 25 October 2016).

40. Aubrecht, D.M.; Helliker, B.R.; Goulden, M.L.; Roberts, D.A.; Still, C.J.; Richardson, A.D. Continuous, long-term, high-frequency thermal imaging of vegetation: Uncertainties and recommended best practices. Agric. For. Meteorol. 2016, 228-229, 315-326. [CrossRef]

41. Schaaf, C. MCD43A3 MODIS/Terra + Aqua BRDF/Albedo Daily L3 Global-500 m V006; NASA: Washington, DC, USA, 2015.

42. Lucht, W.; Hyman, A.H.; Strahler, A.H.; Barnsley, M.J.; Hobson, P.; Muller, J.P. A comparison of satellite-derived spectral albedos to ground-based broadband albedo measurements modeled to satellite spatial scale for a semidesert landscape. Remote Sens. Environ. 2000, 74, 85-98. [CrossRef]

43. Lewis, P.; Barnsley, M. Influence of the sky radiance distribution on various formulations of the earth surface albedo. Proc. Conf. Phys. Meas. Signatures Remote Sens. 1994, 707-715.

44. R Development Core Team. R: A Language and Environment for Statistical Computing; R Foundation for Statistical Computing: Vienna, Austria, 2011.

45. Fox, J.; Weisberg, S. An $\{R\}$ Companion to Applied Regression; Second Edition; Sage Group: Thousand Oaks, CA, USA, 2011.

46. Liu, J.; Schaaf, C.; Strahler, A.; Jiao, Z.; Shuai, Y.; Zhang, Q.; Roman, M.; Augustine, J.A.; Dutton, E.G. Validation of moderate resolution imaging spectroradiometer (MODIS) albedo retrieval algorithm: Dependence of albedo on solar zenith angle. J. Geophys. Res. Atmos. 2009, 114, 1-11. [CrossRef]

(C) 2018 by the authors. Licensee MDPI, Basel, Switzerland. This article is an open access article distributed under the terms and conditions of the Creative Commons Attribution (CC BY) license (http:// creativecommons.org/licenses/by/4.0/). 